\title{
Capital Flows Among the G-7 Nations: A Demographic Perspective
}

\author{
Michael Feroli* \\ Federal Reserve Board \\ Division of Research and Statistics
}

October, 2003

\begin{abstract}
The standard life-cycle model of consumption behavior predicts that a household's age will influence its saving behavior. Moreover, simple national accounting identities reveal that a country's current account balance reflects its savings-investment imbalance. Thus, differences in national age-profiles should affect the current account. To test this theory's plausibility and significance, I simulate a multi-region overlapping generations model that is calibrated to match the demographic differences among the major industrialized countries over the past 50 years. In the model, it is found that these differences can explain some of the observed long-term capital movements in the G-7. In particular, the model does a good job of predicting the size and timing of American current account deficits as well as Japanese current account surpluses.
\end{abstract}

Keywords: International Capital Flows, Demographic Transitions, Current Account Dynamics.

JEL Classification: F21, F47, J10.

${ }^{*}$ I thank Fabrizio Perri for his advice and encouragement. William Baumol, Jess Benhabib, Darrel Cohen and Bill Wascher made helpful comments on earlier drafts of this paper. I also benefitted from conversations with Robin Brooks, Douglas Elmendorf and Gianluca Violante. The views presented are solely those of the author and do not necessarily represent those of the Federal Reserve Board or its staff. Corresponding e-mail: Michael.E.Feroli@frb.gov 


\section{Introduction}

Large and persistent current account imbalances are a common feature of the modern global economy. Perhaps the most well-known examples from recent experience are the Japanese surpluses and the American deficits of the last two decades. While economic theory has made much progress relating short-term aggregate fluctuations to international capital flows, the factors causing longer-term movements are less well-understood.

In this paper I examine whether demographic factors can contribute to our understanding of these long-term capital flows. The reason for suspecting the influence of demographics is that the life-cycle theory of consumption predicts that asset accumulation by households will be influenced by the agent's age. In particular, if the household's labor supply measured in efficiency units displays a hump-shaped pattern-low in the early years of a career, rising, then falling again near retirement age-then consumption smoothing implies that households should acquire savings during their productive middle age years to finance consumption in retirement. The optimal capital stock in each country will also be related to the ageefficiency profile of the agents in the economy. Yet the savings supplied by mature adults will be positive even when they supply little or no labor. In the words of Higgins (1998), "the demographic 'center of gravity' for investment demand should be earlier in the age distribution than that for the savings supply." Thus regions that have a higher proportion of their population in the high savings years should, other things equal, tend to export their excess savings and thus run a current account surplus.

Of course, for a demographic transition to have any effect on the current account there must be heterogeneity in the population structures of the trading partners. While all industrialized nations have experienced population aging in the post-war era, they have done so at considerably different rates. The general pattern has been a baby boom after World War II followed by a baby bust that has persisted to this day. Nevertheless, the timing of this boom-bust cycle and the amplitude of these changes has varied across countries. An exam-

ple of this variation can be seen by comparing the U.S. and Japan. The total fertility rate 
(TFR, the average number of children per woman in her lifetime) in Japan peaked around 1950 above 3.5. By the mid-1950's, Japanese TFR declined to about 2, and it has remained at or below that level since that time. U.S. TFR also reached a high above 3.5. But this peak did not occur until about 1960, ten years after the Japanese peak. Moreover, the baby boom fizzled out more slowly in the U.S. than in Japan; TFR in the U.S. did not dip below 2 until the early-1970's. As a result these two countries now have population structures with markedly different adult cohort sizes. For instance, in 1995 16\% of the U.S. population was in the high saving ages between 45 and 60 , while the same figure for Japan was $22 \%$. Turning from demographics back to economics, we might expect the large proportion of Japanese in their prime saving years to have the effect of depressing asset returns in Japan to the point where Japanese look to hold their savings overseas, where the population is relatively more massed near the 'investment demand center of gravity'. Of course this process of sending savings overseas is synonymous with running current account surpluses. Whether the demographic differences are enough to generate current account imbalances of the magnitude observed in the data is a numerical question that I will seek to answer in the context of a simulated multi-region overlapping generations model.

To preview the findings of those simulations, I find that demographic factors alone can do a good job of accounting for the observed American and Japanese net foreign asset positions, though the model does not do as well in predicting the European net foreign asset position. Most of the deterioration in the North American net foreign asset position, in both the model and the data, takes place in the 1980's and 1990's. For the other countries in the sample, the situation is reversed, with the model predicting current account surpluses throughout the 1980's and 1990's. In the data, such current account surpluses are evident for Japan and Germany but not for the other large European economies. Looking ahead, the model predicts a reversal in current account behavior over the next 30 years as North America begins to export savings and the rest of the G-7 imports savings. Around 2030, the high concentration of echo-boomers in Europe and Japan enter their high savings years and 
push the North American net foreign asset position down again.

The model's implications for North America are particularly noteworthy. The empirical proposition (e.g. Higgins, (1998)) that the presence of a large concentration of 'prime savers' should raise net foreign asset holdings would imply that North America, which has seen a significant increase in the fraction of the population in the prime saving years, should now be exporting savings. The fact that it isn't, according to the model presented here, is because an even greater fraction of the population of North America's trading partners are also in their prime saving years. Thus, the general equilibrium nature of the exercise is crucial for understanding the net foreign asset dynamics of North America.

It is important to note that this analysis is conducted under the assumption that national savings equals private savings. Abstracting away fiscal policy in such a manner may seem like a cavalier assumption given that the fiscal balance has normally attracted considerable attention in the literature surrounding the current account. We have two reasons for doing so. First, fiscal policy is well-studied and we prefer to narrow our focus to a sole driving force-demographics. Second, the experience of the United States in the 1990's, when the twin deficits-fiscal and current account-moved in different directions, suggests that the fiscal story alone is not sufficient to explain long-term trends in the current account.

The literature examining the impact of population on international capital flows has developed only recently. Blanchard (1985) introduces a foreign sector to a small open economy populated with agents that have exponential death probabilities. While this approach is an inventive solution to the aggregation problem inherent in overlapping generations models, it simplifies away too much to be usable for capturing the 'life-cycle' effects that are essential to the logic of this paper's thesis. Further, the analysis in Blanchard is essentially concerned with behavior around the steady state, while the interesting aspects of post-war demographics imply the study of transitional dynamics. Masson and Tyron (1990) and Masson et al. (1990) employ a demographic variable in a multi-region macroeconometric model in order to see the effect on capital flows. Similar econometric models explaining the Japanese current 
account in the context of population aging are reviewed in Horioka (1991). The Japanese case is also examined in Dekle (2000). Higgins (1998) presents an interesting econometric panel study of the influence of age structure on a country's current account balance and finds the effects are significant. Attanasio and Violante (2000) present a two-region overlapping generation model to simulate how differential rates of aging effect the North-South capital flow. Perhaps closest in spirit to the current study are Cutler, Poterba, Summers and Sheiner (1990) and Brooks (2000). Cutler et al. look at the impact of demographics on the capital flows between the U.S. and an aggregate of Europe and Japan. Their analysis is conducted with an infinite horizon planning solution. Despite the considerable differences from the over-lapping generations (OLG) framework we employ, Cutler et al. find surprisingly similar predictions for the size and timing of the U.S. net foreign asset position attributable to demographics. Brooks analyzes a multi-region OLG model. The work presented here differs from Brooks in that each period is five years rather than twenty, thus allowing more informative in-sample predictions, and the emphasis of the current model is shifted to the group of industrialized countries.

The remainder of the paper is organized as follows: the next section presents the model, essentially an overlapping generations model extended to many regions. Section three provides intuition by analyzing that model in a simplified set-up where there are only two regions populated by two-period-lived agents. Section four presents the main results of the paper by describing the calibration and simulation of a many-period-lived agent model. Also discussed in section four is the accuracy of the model's in-sample forecast for international capital flows. Section five concludes.

\section{The Model}

\subsection{Households}

There are $M$ countries in the world. In each country agents live $J$ periods and then die. Agents in each country have identical preferences. An agent in country $m$ chooses a con- 
sumption path to maximize

$$
U\left(c_{t}^{1, m}, c_{t+1}^{2, m}, \ldots, c_{t+J}^{J, m}\right)=\sum_{j=1}^{J} \beta^{j-1} u\left(c_{t+j}^{j, m}\right)
$$

subject to

$$
\begin{aligned}
c_{t}^{j, m}+a_{t+1}^{j, m} & \leq e_{j} w_{t}^{m}+\left(1+r_{t}\right) a_{t}^{j, m} \\
a_{t}^{J+1, m} \geq & 0 \\
& a_{t}^{1, m} \text { given } .
\end{aligned}
$$

Here $c_{t}^{j, m}$ and $a_{t}^{j, m}$ is consumption and the asset holdings of an age- $j$ household in country $m$ at time $t, e_{j}$ is the age-specific labor efficiency coefficient, $w^{m}$ is the wage in country $m$ and $r$ is the net interest rate. In each period, agents inelastically supply one unit of labor. Because this model assumes perfect capital mobility and perfect labor immobility, the wage is indexed by country whereas the interest rate is not. The mass of agents born in country $m$ in period $t$ is $N_{t}^{m}$.

\section{$2.2 \quad$ Firms}

In each country a representative firm operates a Cobb-Douglas production technology to produce the single consumption good using capital and labor. The capital share parameter $\alpha$ is common across countries while the total factor productivity $A$ is allowed to vary across countries and over time. The aggregate capital stock is assumed to depreciate at the rate $\delta$. Output in country $m$ is then

$$
Y_{t}^{m}=A_{t}^{m}\left(K_{t}^{m}\right)^{\alpha}\left(L_{t}^{m}\right)^{1-\alpha}
$$

where the effective labor input $L_{t}^{m}$ is defined

$$
L_{t}^{m}=\sum_{j=1}^{J} e_{j} N_{t+1-j}^{m}
$$


Both capital and labor are paid their marginal product:

$$
\begin{aligned}
r_{t} & =\alpha A_{t}^{m}\left(K_{t}^{m}\right)^{\alpha-1}\left(L_{t}^{m}\right)^{1-\alpha}-\delta \\
w_{t}^{m} & =(1-\alpha) A_{t}^{m}\left(K_{t}^{m}\right)^{\alpha}\left(L_{t}^{m}\right)^{-\alpha} .
\end{aligned}
$$

\subsection{Equilibrium}

The multi-region open economy model is a general equilibrium model; all prices are determined endogenously. Furthermore, perfect capital mobility (and the homogeneity of capital across countries) ensures that capital will flow 'downhill' to capital-poor regions in order to eliminate any arbitrage opportunities. Although the consumer's budget constraint involves only one asset and no financial institutions are explicitly modeled, we assume that there exist a large number of mutual funds who earn zero-profit and allocate the savings entrusted to them such that there is one world interest rate.

Because this is a model where the one good is freely traded, both the terms of trade and the real exchange rate will be one in all periods. Thus, exchange rates will play no further role in the analysis and the one good is used as the numeraire.

In a multi-region open economy model, it is natural to think of allocations as constrained so that global consumption and investment should be no greater than global output. This is equivalent to the condition that global capital demand equals global capital supply, or

$$
\sum_{m=1}^{M} K_{t}^{m}=\sum_{m=1}^{M} \sum_{j=1}^{J} N_{t+1-j}^{m} a_{t}^{j, m} .
$$

Now we are in a position to define an equilibrium for this economy:

Definition 1 A Competitive Equilibrium is a sequence of prices and allocations,

$\left\{r_{t}\right\}_{t},\left\{\left\{w_{t}^{m}, Y_{t}^{m}, K_{t}^{m}\right\}_{t}\right\}_{m},\left\{\left\{\left\{a_{t}^{j, m}, c_{t}^{j, m}\right\}_{t}\right\}_{m}\right\}_{j}$ such that

i) Optimization:

Households maximize (1) subject to (2), (3), and (4), 
Prices are determined by (5) and (6),

ii) Feasibility:

Equation (7) holds for all t,

iii) Capital Mobility:

Equation (5) holds at each $t$ for all $m$,

given exogenous processes for productivity and population, $\left\{\left\{A_{t}^{m}, N_{t}^{m}\right\}_{t}\right\}_{m}$.

\section{The Two-Period, Two-Country Model}

Before proceeding to the calibrated model, this section examines the dynamic behavior of a simple version of the model in order to provide intuition for the results of the computational experiments performed later in the paper. In brief, I specify the parameters and functional forms of the model presented in the previous section when $M=2$ and $J=2$ and solve the model so that a few equations can summarize the response of the economy to an exogenous change in population.

Let the two countries be denoted by $a$ and $b$. In the following specification of the model, only the population $N_{t}^{m}$ will vary between the countries. Utility is assumed to be logarithmic. For ease of exposition, the capital share $\alpha$ is set to $1 / 2, \beta$ is set to 1 , and $\delta$ is set to 0 . The technology parameter $A_{t}^{m}$ is set to 40 for both countries and at all time periods (to generate round numbers). The age-efficiency coefficients are one in the first period of life and zero in the second period of life.

Perfect capital mobility and identical technology parameters ensure that the interest rate, wage rate, and capital-labor ratio, $k_{t}$, are identical in both countries and thus we can drop the country superscripts on these variables. Furthermore, the equalization of prices implies that the households in both countries behave identically.

The first-order condition for the household's optimization problem reduces to the simple rule that each household consumes $1 / 2$ of its labor income in the first period of life, or 


$$
a_{t+1}=1 / 2 \cdot w_{t}
$$

The firms first-order conditions are

$$
\begin{aligned}
& r_{t}=20 \cdot k_{t}^{-1 / 2} \\
& w_{t}=20 \cdot k_{t}^{1 / 2}
\end{aligned}
$$

The equilibrium condition is

$$
\begin{aligned}
K_{t}^{a}+K_{t}^{a} & =N_{t-1}^{a} \cdot a_{t}+N_{t-1}^{b} \cdot a_{t} \quad \text { or } \\
N_{t}^{a} \cdot k_{t}+N_{t}^{b} \cdot k_{t} & =N_{t-1}^{a} \cdot a_{t}+N_{t-1}^{b} \cdot a_{t}
\end{aligned}
$$

When $N$ is stable over time the equilibrium condition can be re-written as

$$
k_{t}=a_{t}
$$

which, in conjunction with the households saving behavior and the wage equation, generates a law of motion for the capital-labor ratio

$$
k_{t+1}=10 \cdot k_{t}^{1 / 2}
$$

The behavior of the world economy through time is now specified. It remains to define the national accounting identities that will characterize the current account balances of the two countries.

Gross national savings in country $m$ is

$$
S_{t}^{m}=N_{t-1}^{m} \cdot a_{t}
$$

The definitions for country $m^{\prime} s$ net asset position (NAP) and current account (CA) follow naturally; 


$$
\begin{aligned}
N A P_{t}^{m} & =S_{t}^{m}-K_{t}^{m} \\
C A_{t}^{m} & =N A P_{t}^{m}-N A P_{t-1}^{m} .
\end{aligned}
$$

The limited number of equations in the two-period, two-country model make it possible to solve by hand the response of the world economy to a population shift in one of the economies. Specifically, consider the case where 100 households are born each period in each country, the generation born in country $a$ in period $t=1$ unexpectedly falls to 50 , and every generation in country a remains size 50 in perpetuity. Solving for the two steady states and the transition path between them, we have

\begin{tabular}{|l|l|l|l|l|l|l|l|l|l|}
\hline & $N^{a}$ & $N^{b}$ & $k$ & $r$ & $w$ & $S^{a}$ & $S^{b}$ & $K^{a}$ & $K^{b}$ \\
\hline $\mathrm{t}=0$ & 100 & 100 & 100 & 2 & 200 & 10000 & 10000 & 10000 & 10000 \\
\hline $\mathrm{t}=1$ & 50 & 100 & 133 & 1.7 & 231 & 10000 & 10000 & 6667 & 13333 \\
\hline $\mathrm{t}=2$ & 50 & 100 & 115 & 1.8 & 215 & 5773 & 11545 & 5773 & 11545 \\
\hline $\mathrm{t}=3$ & 50 & 100 & 107 & 1.9 & 207 & 5373 & 10745 & 5373 & 10745 \\
\hline$\cdot$ & & & & & & & & & \\
\hline$\cdot$ & & & & & & & & & \\
\hline $\mathrm{t}=\infty$ & 50 & 100 & 100 & 2 & 200 & 5000 & 10000 & 5000 & 10000 \\
\hline
\end{tabular}

The international investment positions of the two countries are

\begin{tabular}{|l|l|l|l|l|}
\hline & $N A P^{a}$ & $N A P^{b}$ & $C A^{a}$ & $C A^{b}$ \\
\hline $\mathrm{t}=0$ & 0 & 0 & 0 & 0 \\
\hline $\mathrm{t}=1$ & 3333 & -3333 & 3333 & -3333 \\
\hline $\mathrm{t}=2$ & 0 & 0 & -3333 & 3333 \\
\hline $\mathrm{t}=3$ & 0 & 0 & 0 & 0 \\
\hline$\cdot$ & & & & \\
\hline$\cdot$ & & & & \\
\hline $\mathrm{t}=\infty$ & 0 & 0 & 0 & 0 \\
\hline
\end{tabular}

The effect of a one-time drop in population in country $a$ is clear; country $a$ runs a current account surplus in period one as savings flow from $a$ to $b$ in order to equate the capital per young worker in both countries. In period two, country $a$ dissipates its savings in country $b$. 
While this example illustrates the main thesis that demographic transitions can affect capital flows, three other results of this exercise deserve a brief mention. First, although the equilibrium with open capital markets is efficient, some agents are made worse off during the transition relative to the outcome that would have obtained under closed capital markets. In particular, the first generation of young agents born in the 'baby bust' in the country that experienced the bust would have benefitted from closed capital markets inasmuch as they would have had a higher wage due to the higher capital-labor ratio. Similarly, the generation of older agents who were alive during the 'baby bust' in the country that didn't experience the bust would have been better off with closed capital markets because the rate of return on their savings would not have been negatively impacted by the inflow of foreign capital. Reversing the argument, open capital markets benefit the old in the bust country and the young in the non-bust country relative to what they could have expected under closed capital markets.

Second, a one-time shock that leads to an imbalance in the net asset position of a county will eventually be reversed in an OLG setting as agents consume all their wealth in a finite period of time. This is in contrast to the standard infinite-lived agent model where a onetime shock to a country's net asset position isn't reversed and the annuity value of the foreign asset is consumed each period, creating a constant stream of current account imbalances.

A third result, closely related to the second, is that cultural or institutional factors that affect the saving rate will not affect the current account in a steady state. This result will not hold if one introduces trend output or population growth. Nevertheless, the insight can be useful in clarifying how to think about the current account. Thus, if one introduces country-specific rates of time preference and works through the previous example, it can be seen that the steady state current account is zero. This implies that if one thinks in a finite-lived agent framework about, say, explaining Japanese surpluses through capital market imperfection, then it is still necessary to introduce a transitional process to generate current account imbalances. 


\section{The Many-Period, Many-Region Model}

\subsection{Calibration}

In this section, I specify a version of the model which is intended to be detailed enough to determine how well the model performs against the data. The general idea is as follows: construct a computational model that takes as an input observed population numbers through the year 2000 and projected population numbers for years after 2000. The model will then calculate, among other things, the net foreign asset position for the various regions. If we

find that the model can fit the actual path of the historical capital flows reasonably well, then we can attach some plausibility to the predicted future path of those same flows.

The G-7 is divided into four regions: North America, Japan, the E-3, and Germany. North America comprises the United States and Canada and the E-3 consists of France, Italy, and the U.K. A second version of the world excludes Germany as a fourth region. These simulations are considered separately in order to see whether demographic particularities involving German reunification drive the results of the model. Excluding Germany does not have a major impact, so the main simulations presented include Germany. In these simulations the not wholly satisfactory way in which I count German population is to use West German cohorts before 1990, and to count all German 20-25 year-olds from 1995 onward.

The developing world is left out of the model. The reason for so doing is that the relatively small capital flows between the developing and developed worlds suggest that there exist significant capital market imperfections that would not accord well with the model as presently constructed. One might object that, for instance, the U.S. trades more with Mexico than with Japan, so that leaving Mexico out would jeopardize the realism of the model. However, while it certainly is true that some realism is lost, the fact that the U.S. trade imbalance with Mexico is consistently much smaller than with Japan implies that the net capital flows are much smaller between the U.S. and Mexico than between the U.S. and Japan. Hence, gross trade volume alone may be a misleading indicator of 
how well capital flows between regions. This argument for excluding the developing world is, essentially, the 'political risk' hypothesis that Lucas (1990) conjectured might prevent massive amounts of capital from flowing to poor countries from rich countries. Of course, complete capital immobility between rich and poor countries is an extreme assumption. The analysis presented in Attanasio and Violante looks at demographic effects on capital flows when there is perfect capital mobility between 'north and south.' Using this opposite assumption, their model predicts that demographic effects should lead to massive capital flows from rich to poor countries. Such large flows are not evident in the data, and thus we feel reasonably comfortable restricting the analysis to the G-7 countries.

Agents in this model live with certainty for 12 five-year periods, from age 20 to 80 . The population data, both historical and projected, is from the U.S. Census Bureau's International Data Base. The population counts in the simulation match those in the data for every five-year period between 1950 and 2050. For the hundred years before 1950 and the hundred years after 2050, the population is assumed to be constant at 1950 and 2050 levels, respectively. Extending the exogenous process in this manner allows the transitional dynamics to mostly play themselves out before being forced to the final steady state and is a common technique in the demographic transition literature since Auerbach and Kotlikoff (1987).

The agents' utility function is assumed to be logarithmic. The time discount parameter is set to .82 to match an annualized interest rate of $4 \%$. Age-efficiency coefficients are taken from Hansen (1993). The capital share parameter is set to .3. The technology parameter is constant and set to one for all regions. Equalizing technology across countries may not be a bad first approximation for the period since 1970 and, more importantly, allows the model to focus on demographics as the only source of heterogeneity among the different regions. Capital depreciates at a rate of $22 \%$ every five years, which corresponds to the $5 \%$ annual depreciation rate that is common in the literature. 


\subsection{Simulation}

As in Brooks (2000), I make use of the fact that the equation for world excess demand can be written as solely a function of the capital-labor ratio in the first region. To compute the transition, I first find the initial and final steady-state capital-labor ratio. The excess demand function for each period in the transition will be a nonlinear function of the capital-labor ratio in that period as well as in several leads and lags. Where those leads or lags are outside of the range of periods in the simulation, the capital-labor ratio is set to its respective steadystate value. Solving for the equilibria over the transition reduces to solving this system of nonlinear excess demand functions. Further details are provided in the appendix.

\subsection{Findings}

The data for the Net Foreign Asset (NFA) positions as a percent of GDP for the G-7 are presented in figure 1. For most countries, the series for NFA is of quite recent origin, with very few countries reporting data for earlier than 1980. The balance on the current account, however, is tracked by most countries back to at least 1970. Lane and Milesi-Ferretti (1999), the source of the data in figure 1, make use of the identity that the current account is the first difference of the NFA position and integrate the series' of current account balances to estimate the NFA positions for a collection of countries. However, statistical and accounting discrepancies create a wedge between recently measured NFA positions and the cumulated current account balances. In particular, the cumulated current account data in displayed in figure 1 tend to mildly overstate Japanese NFA and understate North American NFA.

Foreign asset data organized by geographic destination of those assets is unavailable. For example, though we know the amount of foreign assets held in Japan, we do not have a country-specific breakdown of Japanese foreign assets. This shortcoming of the data is largely due to holdings of international securities change hands rapidly. As a result the NFA positions for our two aggregate regions, North America and the E-3, are more properly

interpreted as the maximum of the absolute value of the region's NFA position. This does 
not appear to be a major problem; Lane and Milesi-Ferretti present a true aggregate for the Eurozone's NFA that does not differ significantly from the aggregated data for the E-3 presented in figure 1.

The model's path of each region's net foreign asset position in the baseline case is displayed in figure 2. One of the first things that stands out is that the model fits fairly well the timing of the NFA positions in both North America and Japan.

Comparing the North American net foreign asset position in the model with the data, we can see that the model correctly predicts the long-term decline observed since the early 1980's. In terms of magnitude, in the data the North American NFA/GDP position goes from slightly above zero to $-25 \%$. The model predicts over the same period the North American asset position going from slightly positive to $-9 \%$. The model predicts present Japanese NFA of around $+8 \%$ of GDP, whereas in the data it is around $+30 \%$ of GDP. The German asset path tracks the Japanese path in the model, which is not surprising given their similar demographic structures. In the data, the impact of reunification can be seen in the drop in capital sent abroad by Germans in the 1990's relative to the 1980's. For this reason, the model doesn't explain German foreign asset holdings in the 1990's as well as in the 1980's. The region whose asset path the model has the most trouble explaining is the E-3. The model predicts that the demographic structures of these countries would lead them to accumulate substantial amounts of foreign capital, whereas in the data this accumulation has not taken place.

Figure 3 shows the simulation excluding Germany. This simulation is presented to demonstrate that inclusion of Germany in the world economy does not have major implications for the model predictions for the other G-7 countries.

If one accepts that the model fits the past data fairly well, what can we say about the future? The future path of the exogenous population process can be predicted relatively well, i.e. we know with a decent amount of certainty how many people 20 years and older there will be 20 years from now. Thus, we can feed this exogenous process into the model 
to obtain the predicted future paths for the capital flows among the G-7. Figure 4 presents the foreign asset positions when the population processes follow the paths projected by the Census Bureau.

According to the model, the projected population flows will cause the North American and Japanese current account positions to reverse themselves over the next 20 years as the large cohort of Japanese baby-boomers who will then be in retirement divest themselves of their accumulated overseas assets. The acute bimodality of the Japanese population age-structure will then make itself felt 30-40 years out as the Japanese echo-boomers enter their prime-saving years and repeat the experience of the 1980's and 1990's. The predicted imminent North American current account surpluses are apparently also driven by the fact that the North American baby boom lasted slightly longer than the Japanese baby boom and hence there will still be significant numbers of American boomers who have not yet retired by the year 2025. Again, given the similarity of Japanese and German demographics, it is not surprising that the German predicted experience should resemble the Japanese case. As we noted earlier, this model's predictions for the North American net foreign asset position are quite similar to the findings of Cutler et al., despite the fact that Cutler et al.'s analysis uses an infinite-horizon model, a fundamentally different framework for modelling demographic dynamics than the OLG model we use here.

\section{Conclusion}

The aim of this paper has been to examine whether demographics has been a significant cause of the long-term capital flows experienced by the major economies over the past two decades. I have attempted to address this issue by observing the behavior of an artificial world economy where the number of agents in the different regions of the economy are calibrated to match the historical and projected data. Before assessing how well the model matches specific episodes, it is worth noting one simpler result: according to the model presented above, foreign asset positions of the magnitude observed in the data can arise as 
equilibrium phenomena when the only exogenous variable allowed to fluctuate is population. In other words, when the economy is shocked by population changes resembling those that have occurred over the last 50 years, the regions routinely display NFA positions whose magnitude is in the ballpark of what we actually see in the data. Indeed, the fact that the model predicts some of the large and persistent capital movements among the major economies in the 1980's and 1990's suggests that the model may have captured a feature of reality that is driving international foreign asset positions.

The two regions for which the model best fits the data are Japan and North America. This fact is interesting for two reasons. First, among the G-7 countries, Japan and North America stand at opposite ends of the demographic spectrum; population aging is occurring most rapidly in Japan and least rapidly in North America. Second, the current account imbalances of Japan and the U.S. have been among the most persistent and puzzling feature of international macroeconomics over the past two decades. The results of the simulations presented above suggest that demographics may play an important role in understanding this puzzle. Of course, to admit this finding is not meant to challenge theories of the current account that rest on cyclical explanations. Rather, the demographic explanation complements such theories by providing an explanation for the current account trend, whereas most other theories explain the current account cycle.

\section{Appendix}

This appendix describes the solution procedure for the multi-period, multi-region overlapping generations model. The household living in country $m$ chooses a consumption path to maximize

$$
U\left(c_{t}^{1, m}, c_{t+1}^{2, m}, \ldots, c_{t+J}^{J, m}\right)=\sum_{j=1}^{J} \beta^{j-1} u\left(c_{t+j}^{j, m}\right)
$$

subject to 


$$
\begin{aligned}
c_{t}^{j, m}+a_{t+1}^{j, m} & \leq e_{j} w_{t}^{m}+\left(1+r_{t}\right) a_{t}^{j, m} \\
a_{t}^{J+1, m} \geq & 0 \\
& a_{t}^{1, m} \text { given } .
\end{aligned}
$$

Here $c$ is consumption, $a$ is the asset holding, $e_{j}$ is the age-specific labor efficiency coefficient, $w^{m}$ is the wage in country $m$ and $r$ is the net interest rate. In each period, agents inelastically supply one unit of labor. The solution to this problem yields a consumption path that satisfies the following two equations:

$$
\begin{aligned}
& c_{t}^{1, m}=\Theta^{-1} \cdot \Lambda_{t}^{m}, \\
& c_{t}^{j, m}=\beta\left(1+r_{t}\right) \cdot c_{t-1}^{j-1, m} \text { for } j=2, \ldots, 12,
\end{aligned}
$$

where

$$
\begin{aligned}
\Theta & =\sum_{i=0}^{11} \beta^{i} \\
\Lambda_{t}^{m} & =\sum_{i=0}^{8} \frac{e_{i+1} \cdot w_{t+i}}{\prod_{j=0}^{i}\left(1+r_{t+j}\right)} .
\end{aligned}
$$

Given the path for consumption the savings of a $j$-period old agent in country $m$ at time $t$ can be written as,

$$
s_{t}^{j, m}=\left(1+r_{t}\right) \cdot s_{t-1}^{j-1, m}+e_{t} \cdot w_{t}^{m}-c_{t}^{j, m} .
$$

World savings at time $t, S_{t}$, can be written as,

$$
S_{t}=\sum_{m=1}^{M} \sum_{j=1}^{12} s_{t}^{j, m} \cdot N_{t+1-j}^{m}
$$


As noted in the text, labor and capital prices are determined by marginal productivities, in particular,

$$
\begin{aligned}
r_{t} & =\alpha A_{t}^{m}\left(K_{t}^{m}\right)^{\alpha-1}\left(L_{t}^{m}\right)^{1-\alpha}-\delta \\
w_{t}^{m} & =(1-\alpha) A_{t}^{m}\left(K_{t}^{m}\right)^{\alpha}\left(L_{t}^{m}\right)^{-\alpha}
\end{aligned}
$$

The assumption of perfect capital mobility, which implies a single world interest rate, also allows us to determine wages in one country relative to another. Thus, the wage in country $p$ relative to the wage in country 1 is,

$$
w_{t}^{p}=\left(\frac{A_{t}^{p}}{A_{t}^{1}}\right)^{\frac{1}{1-\alpha}} w_{t}^{1} .
$$

If we denote the capital-labor ratio in country 1 as $k_{t}^{1}$, then we can write the capital stock in country $m$ as

where

$$
K_{t}^{m}=k_{t}^{1} \cdot L_{t}^{m} \cdot\left(\frac{A_{t}^{m}}{A_{t}^{1}}\right)^{\frac{1}{1-\alpha}}
$$

$$
L_{t}^{m}=\sum_{j=1}^{J} e_{j} N_{t+1-j}^{m} .
$$

Summing over countries gives the world capital demand, $K_{t}$, as,

$$
K_{t}=\sum_{m=1}^{M} K_{t}^{m} .
$$

The vector of excess capital demands, $\varepsilon$, is

$$
\left\{\varepsilon_{t}=K_{t}-S_{t}\right\}_{t=1}^{T}
$$

This vector $\varepsilon$ is a nonlinear system of equations. The root of this system, $\left\{k_{t}^{1}\right\}_{t=1}^{T}$, will determine all the other endogenous equilibrium variables in the economy. This root is found using a standard Gauss-Newton nonlinear least squares procedure. 


\section{References}

[1] Attanasio, Orazio P. and Gianluca L. Violante (2000) "The Demographic Transition in Closed and Open Economies: A Tale of Two Regions" mimeo.

[2] Auerbach, Alan and Laurence Kotlikoff (1987) Dynamic Fiscal Policy, Cambridge University Press

[3] Blanchard, Olivier J. (1985) "Debt, Deficits, and Finite Horizons" Journal of Political Economy, Vol. 93, No. 2: 223-247

[4] Brooks, Robin (2000) "Population Aging and Global Capital Flows in a Parallel Universe" IMF, Working Paper/00/151

[5] Cutler, David M., James M. Poterba, Louise M. Sheiner and Lawrence H. Summers (1990) "An Aging Society: Opportunity or Challenge?" Brookings Papers on Economic Activity, Vol. 1990, No. 1: 1-56

[6] Dekle, Robert (2000) "Demographic Destiny, Per-Capita Consumption and the Japanese Saving-Investment Balance" Oxford Review of Economic Policy, Vol. 16, No. 2: 46-60

[7] Hansen, Gary D. (1993) "The Cyclical and Secular Behavior of the Labor Input: Comparing Efficiency Units and Hours Worked" Journal of Applied Econometrics, Vol. 8, No. 1: $71-80$

[8] Higgins, Matthew (1998) "Demography, National Savings and International Capital Flows" International Economic Review, Vol. 39, No. 2: 343-369

[9] Horioka, Charles Yuji (1991) "Future Trends in Japan's Saving Rate and the Implications thereof for Japan's External Imbalance" Japan and the World Economy, Vol. 3, No. 4: $307-330$ 
[10] Lane, Philip and Gian Maria Milesi-Ferretti (1999) "The External Wealth of Nations: Measures of Foreign Assets and Liabilities for Industrial and Developing Nations" CEPR Discussion Paper No. 2231

[11] Lucas, Robert E., Jr. (1990) "Why Doesn't Capital Flow from Rich to Poor Countries?" American Economic Review, Vol. 80, No. 2: 92-96

[12] Masson, Paul, Steven Symansky and Guy Meredith (1990) "Multimod Mark II: A Revised and Extended Model" IMF, Occasional Paper No. 71

[13] Masson, Paul and Ralph Tryon (1990) "Macroeconomics Effects of Projected Population Aging in Industrial Countries" IMF Staff Papers, Vol. 37, No. 3: 453-485

[14] Weil, David N. (1994) "The Saving of the Elderly in Micro and Macro Data" Quarterly Journal of Economics, Vol. 109, No. 1: 55-81 


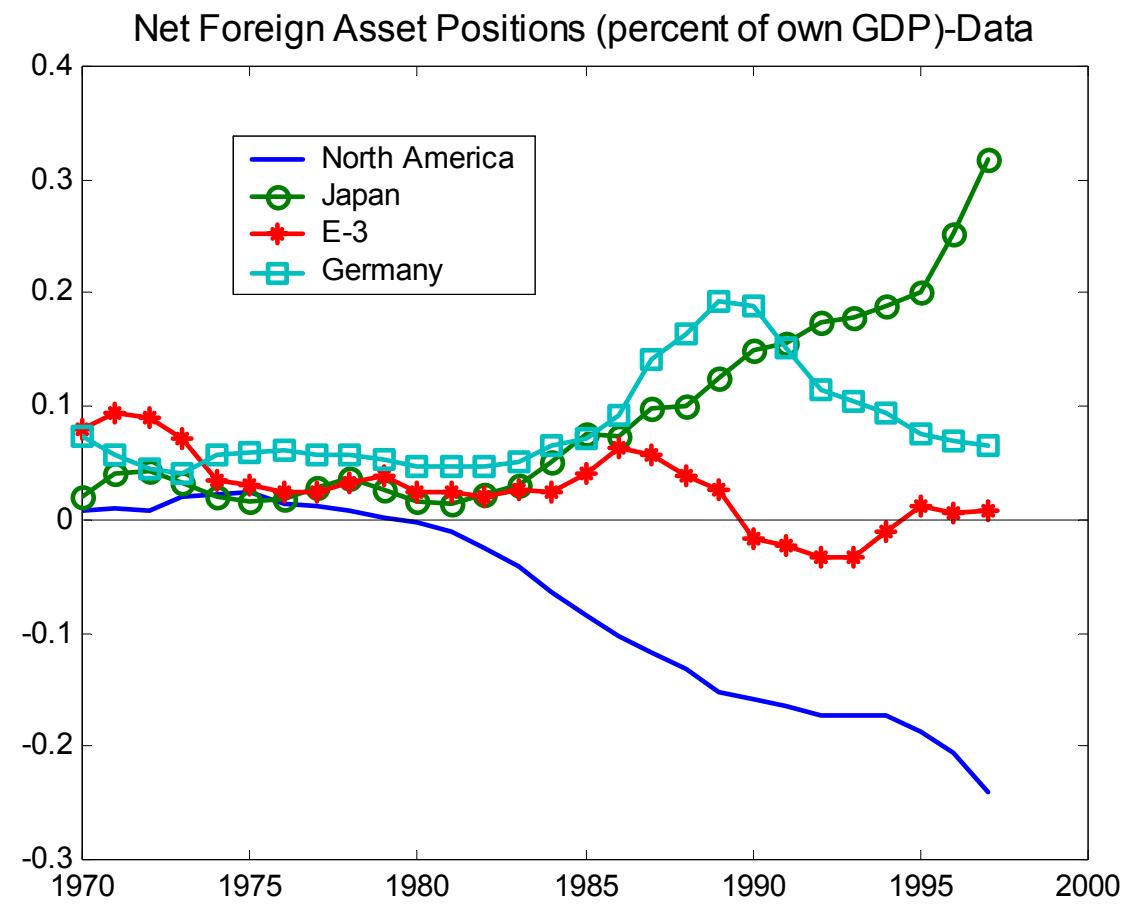

Figure 1 


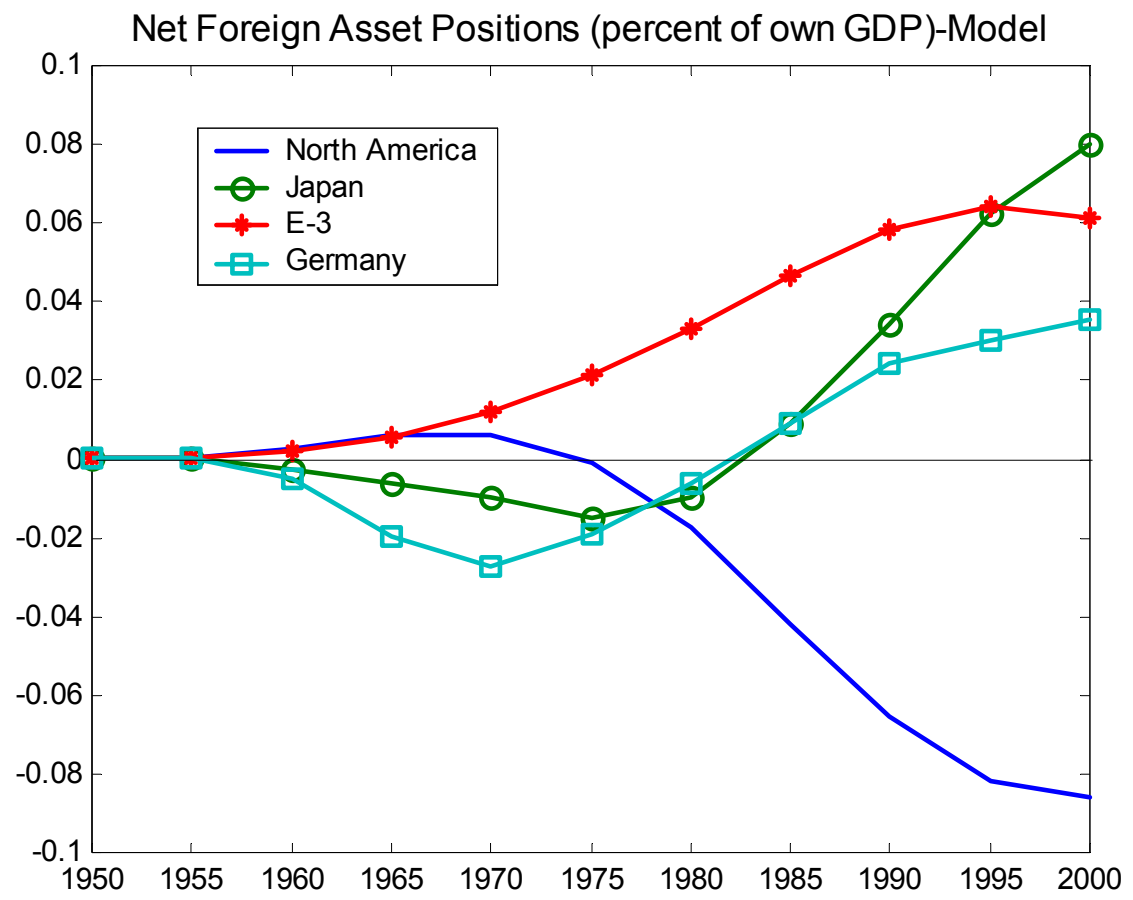

Figure 2 


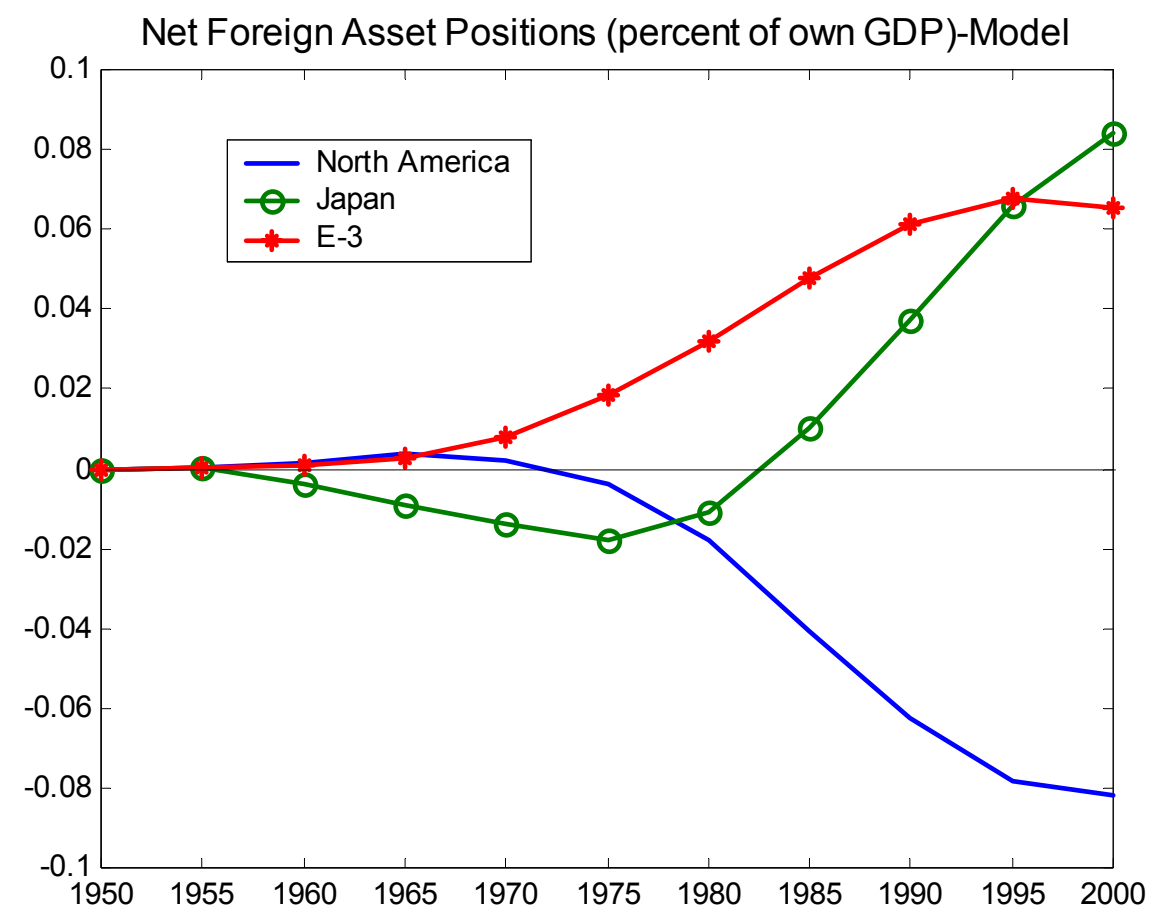

Figure 3 


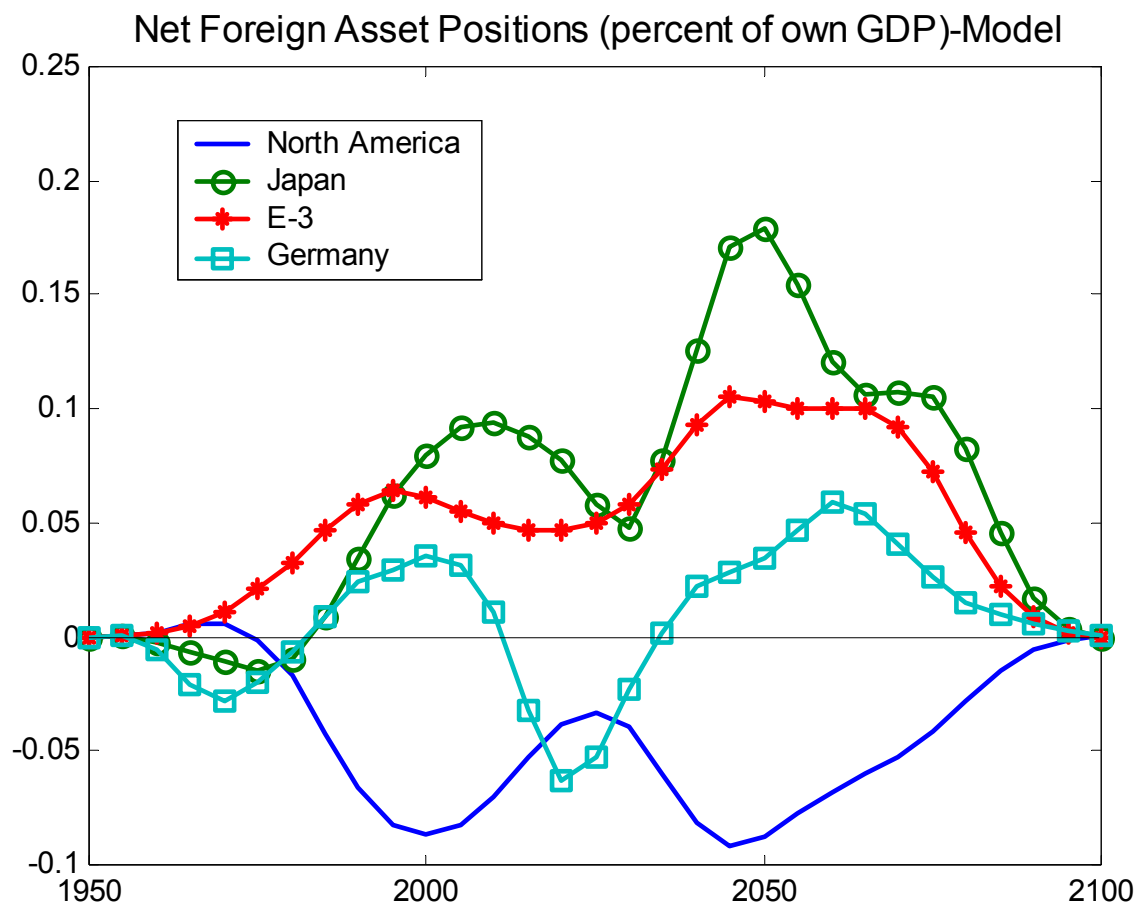

Figure 4 